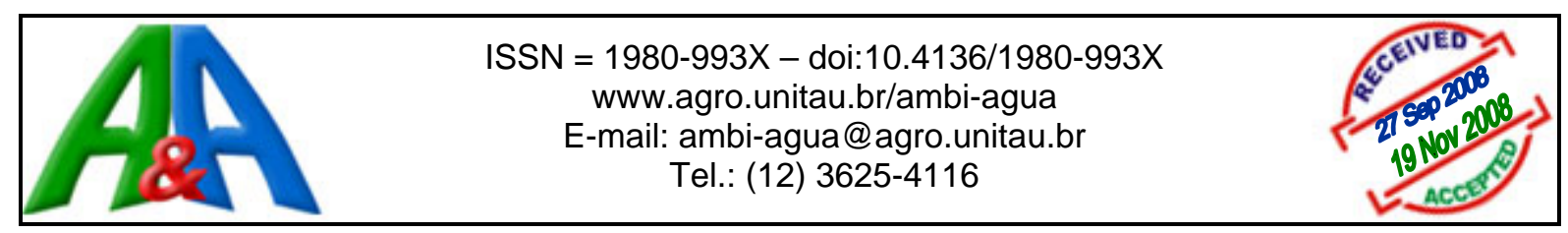

\title{
Avaliação da qualidade da água dos mananciais na ilha de Fernando de Noronha
}

(doi:10.4136/ambi-agua.66)

\author{
Maurício da Motta ${ }^{1}$; Valdinete L. Silva ${ }^{1}$; Abelardo A. A. Montenegro ${ }^{2}$; Suzana \\ M. G. L. Montenegro ${ }^{3}$; Marcus M. Correa ${ }^{2}$ \\ ${ }^{1}$ Departamento de Engenharia Química - Universidade Federal de Pernambuco, R. Prof. Arthur de Sá, s/n \\ Cidade Universitária - CEP: 50740-521 - Recife - PE - Brasil \\ E-mail: \{mottas, vlins\}@ufpe.br \\ ${ }^{2}$ Departamento de Tecnologia Rural, UFRPE \\ E-mail: monte@hotlink.com.br; metri@ufrpe.br \\ ${ }^{3}$ Departamento de Engenharia Civil, UFPE \\ E-mail: suzanam@ufpe.br
}

\section{RESUMO}

O arquipélago de Fernando de Noronha é formado por 21 ilhas. A maior delas é abastecida por dois açudes, uma placa coletora de água da chuva e um sistema de dessalinização de água do mar. Além desses reservatórios e sistemas auxiliares, a ilha conta ainda com outros 6 açudes e alguns poços. Todavia, durante o período de estiagem, a ilha sofre escassez de água, que compromete inclusive a capacidade turística, maior fonte de renda local. Dentro desse escopo buscou-se avaliar a qualidade de água de diversos mananciais, para utilização no abastecimento. Foram realizadas medidas "in loco" e análises físicoquímicas em laboratório. Concluiu-se que se faz necessária uma re-estruturação do sistema de abastecimento da ilha para evitar novos problemas de racionamento e risco de colapso.

Palavras-chave: monitoramento; qualidade da água; eutrofização.

\section{Water Quality Evaluation of the Springs in Fernando de Noronha Island}

\begin{abstract}
The Fernando de Noronha archipelago is composed by 21 islands. The biggest of them, the Fernando de Noronha island, is supplied in domestic water by two reservoirs, one rainwater collecting system and another system using sea water desalinization. In addition, this island is supplied by water from six secondary artificial ponds and some wells and springs. However, during the summer drought time, the island endures a water supply reduction that endangers the touristic activities, which are the main economical local financial source. In this concern, were evaluated the quality of the water from several sources for human supplying. Some measurements were performed "in site" and laboratory physical chemical analyses as well. It could be concluded that a further reorganization of the water supply system ought to be carried out in order to avoid future problems and risk of water supply collapse in this island.
\end{abstract}

Keywords: monitoring; water quality; eutrofization. 


\section{INTRODUÇÃO}

O Arquipélago de Fernando de Noronha localiza-se nas coordenadas $3^{\circ} 54^{\prime} \mathrm{S}$ de latitude e $32^{\circ} 25^{\prime} \mathrm{W}$ de longitude a $545 \mathrm{~km}$ de Recife, capital do estado de Pernambuco, e a $360 \mathrm{~km}$ de Natal, capital do estado do Rio Grande do Norte; formado pelo topo das montanhas de uma cordilheira de origem vulcânica, sua base se localiza a cerca de $4.000 \mathrm{~m}$ de profundidade, a Dorsa Mediana do Atlântico, e é constituído por 21 ilhas, rochedos e ilhotas, no total aproximado de $26 \mathrm{~km}^{2}$, tendo a ilha principal $17 \mathrm{~km}^{2}$ de área. A ilha se compõe de dois tipos de rocha, vulcânica e sedimentar, que se dividem nas formações Remédios, Quixaba e São José, em que os solos são desenvolvidos de tufos da formação Remédios (Rocha et al., 2005).

Fernando de Noronha é a ilha principal do arquipélago e a única habitada. Mais de três mil pessoas vivem nessa ilha remanescente dos diversos regimes implantados no arquipélago. São descendentes de prisioneiros, de militares, de pessoas que vieram a prestar serviços que ali permaneceram ou turistas atraídos pelo arquipélago e que nele passaram a viver.

O Arquipélago de Fernando de Noronha é constituído por duas Unidades de Conservação Federais do Instituto Brasileiro do Meio Ambiente e dos Recursos Naturais Renováveis (IBAMA): Área de Proteção Ambiental de Fernando de Noronha (APA-FN) e Parque Nacional Marinho de Fernando de Noronha (Parnamar-FN). O Parnamar-FN compreende aproximadamente 50\% da área da Ilha Fernando de Noronha, todas as demais 17 ilhas secundárias do Arquipélago e a maior parte das águas adjacentes até a profundidade de 50 metros, totalizando uma área de $112,7 \mathrm{~km}^{2}$. Na APA-FN está localizada toda a ocupação permanente de moradia, agropecuária, indústria hoteleira, prestação de serviço e instalações de infra-estrutura (Silva Jr., 2003).

Em 1992, primeiro ano em que o Departamento de Controle Migratório da Administração do Distrito Estadual de Fernando de Noronha obteve dados precisos da entrada de visitantes na ilha, 10.094 turistas foram contabilizados. Ao longo do ano de 2002, a ilha recebeu 62.551 visitantes, um aumento de 520\% em 10 anos. De 1988 a 2002, a população residente da Ilha (permanente e temporária) passou de 1.500 para 3.200, devido à imigração de pessoas que vieram ocupar os postos de serviços criados pelo turismo. A população incidente máxima (moradores permanentes, moradores temporários e visitantes que ocupam simultaneamente a ilha) passou de 1.600, em 1988, para 4.200 pessoas em 2002. Em junho de 2003, o Arquipélago contava com quatro hotéis e 108 hospedarias domiciliares, com capacidade total de 1260 leitos (Silva Jr., 2003).

Devido à privilegiada localização do arquipélago, o clima reinante é o tropical semiúmido de tendência a semi-árido, com baixa pluviosidade média anual $\left(1.200 \mathrm{~mm} / \mathrm{m}^{2}\right)$. O mês de julho é o mais frio (Barros, 1959). Está sob o domínio dos ventos alísios de sudeste. A temperatura média anual é de $27^{\circ} \mathrm{C}$.

Pode ser observado, pela Figura 1, que o comportamento das chuvas permanece o mesmo da média histórica, apesar de apresentar valores bem mais baixos para o ano de 2005 . Segundo Carvalho (1999), o período que vai do fim do mês de fevereiro até o fim do mês de agosto é conhecido como inverno, responsável pelos maiores índices de precipitação pluviométrica na ilha. Do inverno depende o nível de reserva dos açudes e, conseqüentemente, o abastecimento de água do arquipélago. 


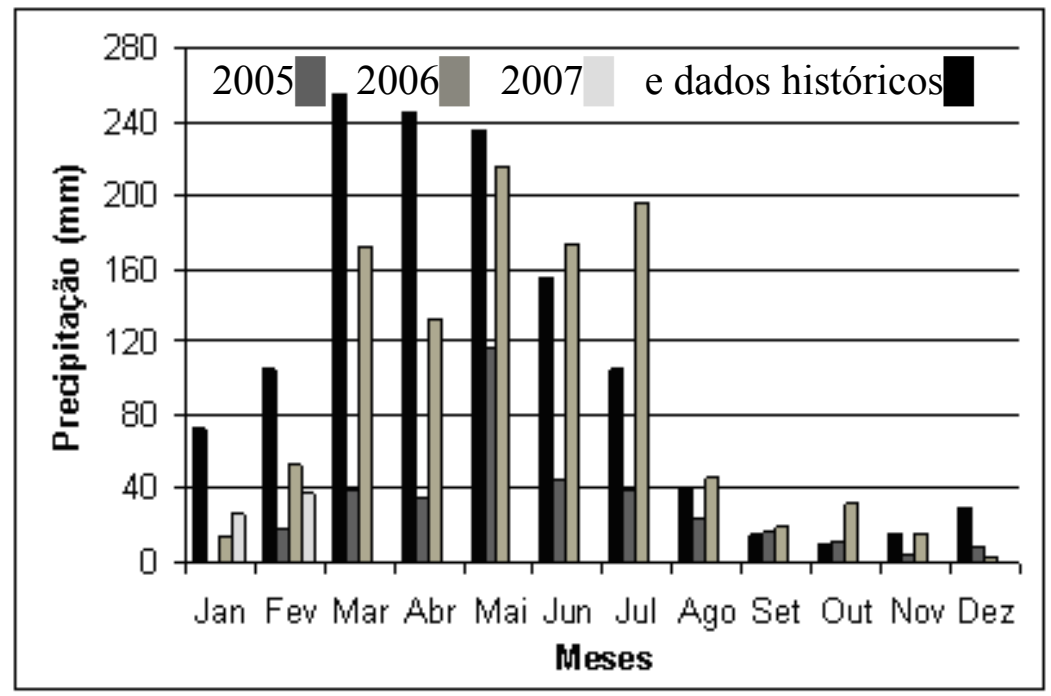

Figura 1. Dados de precipitação na ilha de Fernando de Noronha para os anos de 2005, 2006 e 2007 e dados históricos (Carvalho, 1999) para o período de 1976 a 1997.

Para o fornecimento de água potável, a Companhia Pernambucana de Águas e Esgoto (COMPESA), utiliza o açude do Xaréu como ponto de captação. Esse açude, que tem uma capacidade máxima de armazenamento de $200.000 \mathrm{~m}^{3}$, quando abastecido tem uma produção de 4,2 L/s (aproximadamente $362 \mathrm{~m}^{3} / \mathrm{dia}$ ) (Carvalho, 1999). Ele está atualmente sendo dragado e os aguapés da superfície estão sendo retirados, ampliando a capacidade de armazenamento para $300.000 \mathrm{~m}^{3}$. O açude da Pedreira, que também é utilizado em pequena escala no abastecimento da ilha, tem uma capacidade de $24.000 \mathrm{~m}^{3}$ (Carvalho, 1999). Além desses dois açudes, a ilha dispõe ainda de 6 outros, que são utilizados na dessedentação de animais e na irrigação, encontrando-se atualmente dois deles completamente assoreados (Boldró e Borges). A Figura 2 mostra a localização de alguns desses açudes. Além destes açudes, a ilha conta ainda com uma placa coletora de água da chuva e com um sistema de dessalinização que fornece $36 \mathrm{~m}^{3} / \mathrm{h}$, durante 20 horas por dia. Esse sistema de dessalinização passou por uma série de ampliações desde a sua implantação no ano 2000, alcançando a produção atual em fevereiro de 2006 (COMPESA, 2007). Além desses mananciais, a ilha dispõe de 44 poços, sendo 4 utilizados pela companhia de abastecimento, dos quais destacamse: o do QG, que está acoplado a um sistema de dessalinização, fornecendo água em garrafões de 20 litros; o da Vila da Aeronáutica e o da Caieira utilizados para distribuição de água em carros-pipa. Esses últimos apresentam contaminação por coliformes, segundo Da Motta e Pereira (2006) e Da Motta (2005).

Apesar desses reservatórios e sistemas auxiliares, a ilha sofre falta de água, comprometendo inclusive a sua capacidade turística, que é a sua maior fonte de renda. Dentro desse escopo, buscou-se avaliar a qualidade de água de outros mananciais, para sua posterior utilização no abastecimento, assim como aumentar a capacidade de armazenamento de água da ilha. Neste trabalho serão apresentados os resultados do monitoramento e da avaliação. 


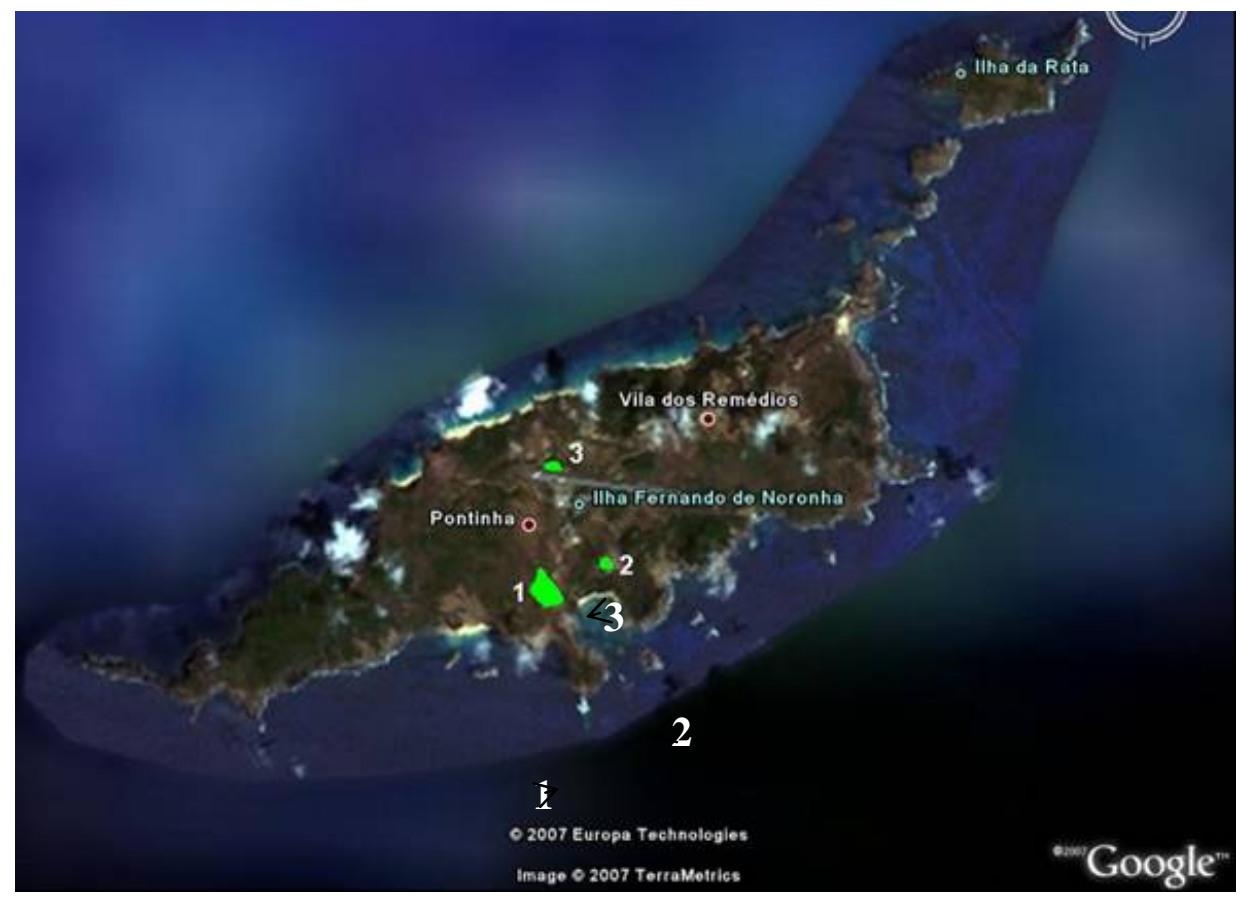

Figura 2. Localização dos açudes Xaréu (1), Pedreira (2) e Emas (3) na ilha de Fernando de Noronha.

\section{MATERIAIS E MÉTODOS}

Para a avaliação da qualidade dos mananciais, tanto no que diz respeito a viabilidade da sua utilização como na qualidade da água foram realizadas observações e análises químicas das águas "in situ" e no laboratório. No primeiro caso, além de avaliar os mananciais como fonte de recursos hídricos foram analisados a concentração de oxigênio dissolvido, condutividade elétrica, temperatura da água e teor de sólidos totais dissolvidos. Para a realização das análises físico-químicas e microbiológicas no laboratório, foram feitas coletas em pontos determinados e as amostras preservadas e acondicionadas em caixas térmicas e transportadas no mesmo dia até o local das análises. Foram realizadas as seguintes determinações, seguindo-se a metodologia do Standard Methods for the Examination of Water and Wastewater (APHA, 1995): pH através de pHmêtro Digimed modelo TM-20; demanda química de oxigênio (DQO) (Método $5220 \mathrm{C}$ ); demanda bioquímica de oxigênio $\left(\mathrm{DBO}_{5}\right.$ ) (Método 5210B); sólidos totais (ST) (Método $2540 \mathrm{~B}$ ); sólidos Fixos (SF) e sólidos voláteis (SV) (Método $2540 \mathrm{E}$ ); fósforo - $\mathrm{P}$ (Método 4500-P C), nitrogênio amoniacal $\left(\mathrm{NNH}_{3}\right.$ ) (Método 4500- $\mathrm{NH}_{3} \mathrm{C}$ ); nitrogênio total- NT (Método 4500-N C); cloretos (Método $4500 \mathrm{Cl}^{-} \mathrm{B}$ ); salinidade medida através de condutivímetro Schott modelo handylab LF1 e a concentração de oxigênio dissolvido foi determinada por meio de um oxímetro Schott, modelo handylab OX1.

Foram realizadas coletas desses mananciais nos meses de julho, setembro e novembro de 2004 e em fevereiro, maio, agosto e outubro de 2005. Serão apresentados os resultados da avaliação e monitoramento de três açudes da ilha de Fernando de Noronha, sendo dois deles utilizados para o abastecimento de água potável da ilha (Xaréu e Pedreira) e um para a irrigação (Emas). Diante da problemática da escassez de água, gerada por um mau gerenciamento desse recurso na ilha, acentuada por uma escassez de chuva, avalia-se aqui também a possibilidade da utilização deste último para o abastecimento de água. 


\section{RESULTADOS E DISCUSSÃO}

Foi constatada, em vários reservatórios da ilha, a existência de uma espécie de aguapé conhecido como Alface d'água (Pistia stratiotes). A aguapé deteriora a qualidade da água, aumenta as perdas de água nos reservatórios, devido à evapotranspiração, e pode ainda favorecer a disseminação de doenças. O Pistia stratiotes (Figura 3), também é conhecido como pasta, alface d'água, mururé, lentilha d'água, dentre outros nomes (PLANTAMED, 2005). No Brasil, no momento, não há nenhum herbicida registrado para controle de aguapé, e a maioria das pesquisas trabalha com herbicidas em condições controladas ou em pequenos corpos hídricos sem fluxo de água.
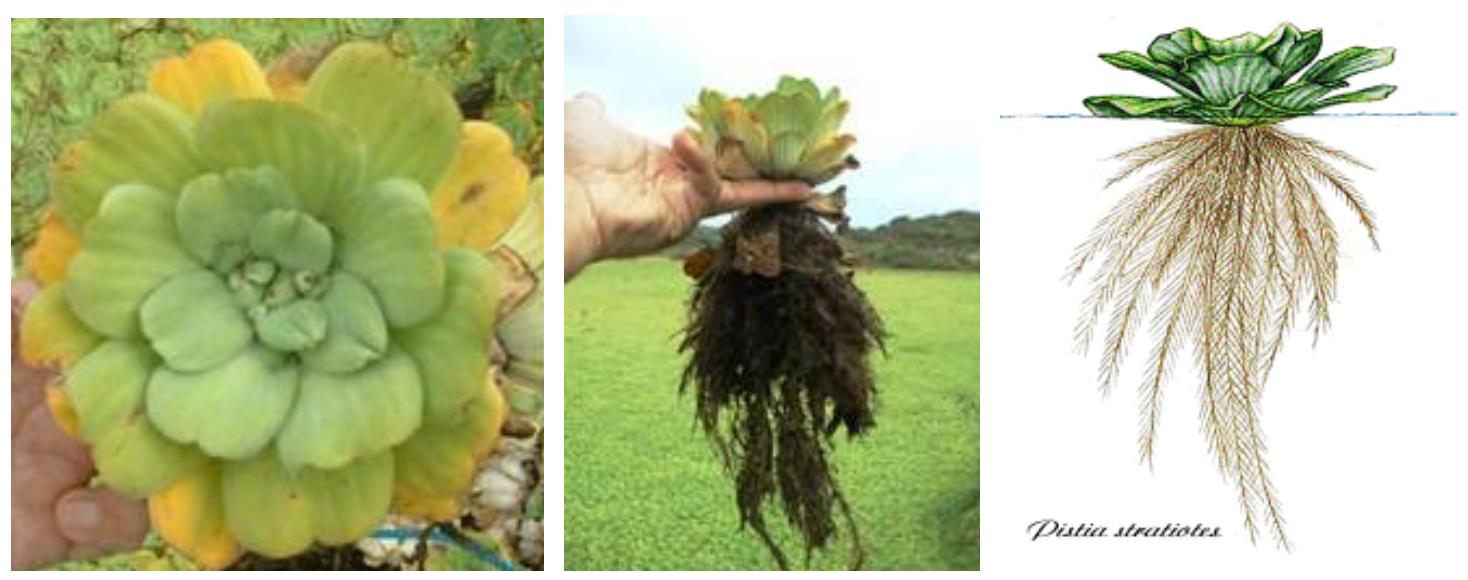

Figura 3. Fotos e figura do aguapé.

Fonte: Fotos dos autores e figura de PLANTAMED (2005).

As plantas de $P$. stratiotes são espécies cosmopolitas com ampla distribuição por todo o planeta (University of Florida, 2004 apud Carvalho et al., 2005). P. stratiotes é uma planta aquática perene, flutuante livre, nativa da América Tropical e que se propaga por estolões. Por ter sua água utilizada para o abastecimento, a utilização de herbicidas nesses reservatórios não seria indicada, podendo assim ser indicada a sua remoção e valoração. PLANTAMED (2005) cita, entre outras indicações das folhas desse aguapé, a sua utilização em casos de asma, diabete insípida, diarréia e enfermidades dos rins e da bexiga. Dessa forma, estaria se controlando o desenvolvimento desse aguapé e ofertando uma fonte de renda para a população local.

Com o aumento da população, principalmente em ambientes rurais, o fósforo que é um nutriente essencial para o cultivo de vegetais e criação de gado, quando exportado dessas áreas devido a enxurradas, pode atingir o ambiente aquático, promovendo dessa maneira o enriquecimento da água e desencadeando o processo de eutrofização (Sharpley et al., 1999). Uma vez que o fósforo é elemento chave para a eutrofização dos sistemas aquáticos, muita atenção deve ser dada a sua ciclagem entre o sedimento e a água intersticial, bem como à liberação do fósforo solúvel do sedimento para a coluna de água (Koski-Vahalae e Hartikainen, 2001). As reações de adsorção-dessorção parecem controlar as trocas de fósforo em solos minerais. A capacidade de adsorção dos sedimentos suspensos tem demonstrado ser mais alta do que as partículas da superfície do solo porque os processos erosivos seletivamente transportam partículas finas com alta capacidade de fósforo adsorvido (Sharpley, 1980).

O nitrogênio é o nutriente limitante para o crescimento da maioria das plantas em solos agrícolas. Assim, para o aumento da produção agrícola são utilizadas quantidades cada vez 
maiores de fertilizantes, que liberam grande quantidade de nitrogênio orgânico e inorgânico para o meio ambiente (Muchovej e Recgcigl, 1994). O uso excessivo de nitrogênio, além da capacidade de fixação pelas plantas, parece ser a principal fonte de nitrato tanto para a água superficial quanto para a água subterrânea em áreas agrícolas, principalmente nos locais onde a aplicação de fertilizantes com nitrogênio ou esterco ocorre antes de picos de chuva (Kirchmann, 1994). A concentração de nitrogênio na enxurrada, especialmente sob a forma de nitrato, está associada a diversos fatores, dentre eles a umidade anterior do solo, propriedades do solo, declividade e às práticas agrícolas como tipo de cultivo, época de aplicação e forma de incorporação ao solo (Owens, 1994).

\section{Açude Xaréu}

Por ser o principal fornecedor de água para a ilha, esse açude teve um acompanhamento mais intensivo e detalhado. Foi constatada aqui também a presença de aguapés Pistia stratiotes. Esses aguapés devem ser retirados para uma melhor oxigenação da água e minimização da evaporação (Pott e Pott, 2000). A limpeza das suas bordas e a colocação de uma cerca no seu entorno contribuiriam significativamente para a melhoria da qualidade da água, uma vez que reduziriam o contato dos animais, e seus resíduos, com a água do açude.

A Figura 4 apresenta a variação do nível do açude Xaréu no ano de 2004. Pode ser observado um decréscimo acentuado no volume desse corpo hídrico devido à reduzida pluviosidade e elevada isolação, que contribuem para uma alta taxa de evaporação e o crescimento dos aguapés, o que aumenta a perda de água pela evapotranspiração. No início de 2005 foi parado o monitoramento do nível desse açude por problemas nas réguas e o baixo nível que ele atingiu.

O nível desse açude chegou a seu mínimo para captação em fevereiro de 2006. Período em que todos os açudes da ilha atingiram seu nível mínimo. Após esse período, continuou-se a captação de água, mas apenas da água perdida que passa sob o paredão, que é captada através de um sistema de drenagem que encaminha essa água para um poço (Figura 5).

Em termos de monitoramento, verificou-se a necessidade de analisar um ponto na entrada de água do açude, para verificar a entrada de possíveis contaminantes, como resíduos de agrotóxicos ou fertilizantes. Estes podem causar a eutrofização do açude, o que explicaria a elevada concentração de aguapés que cobrem toda a sua superfície.

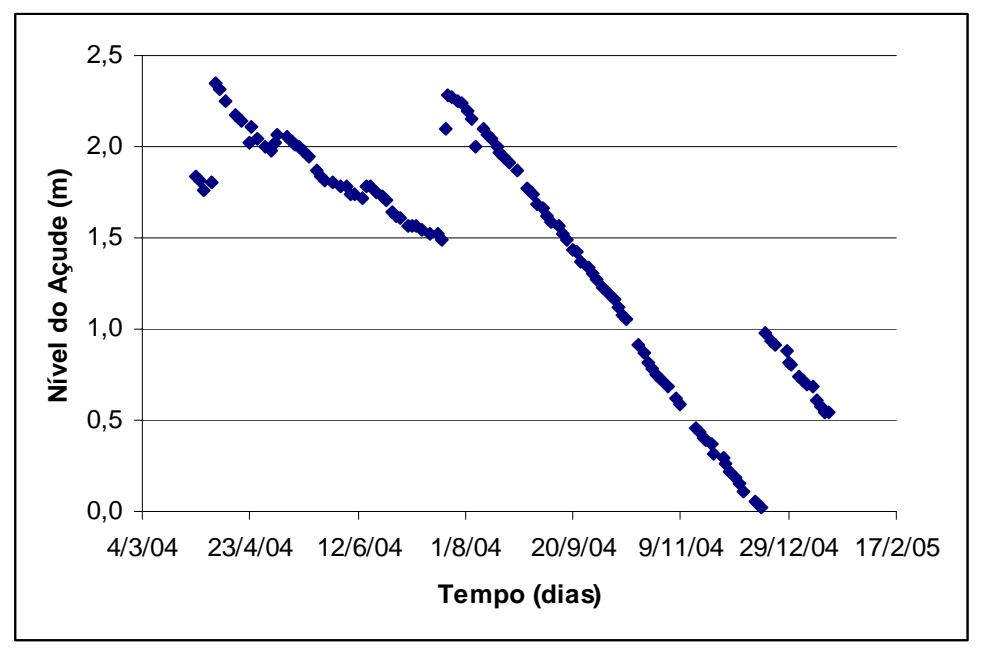

Figura 4 - Variação do nível do açude Xaréu. 


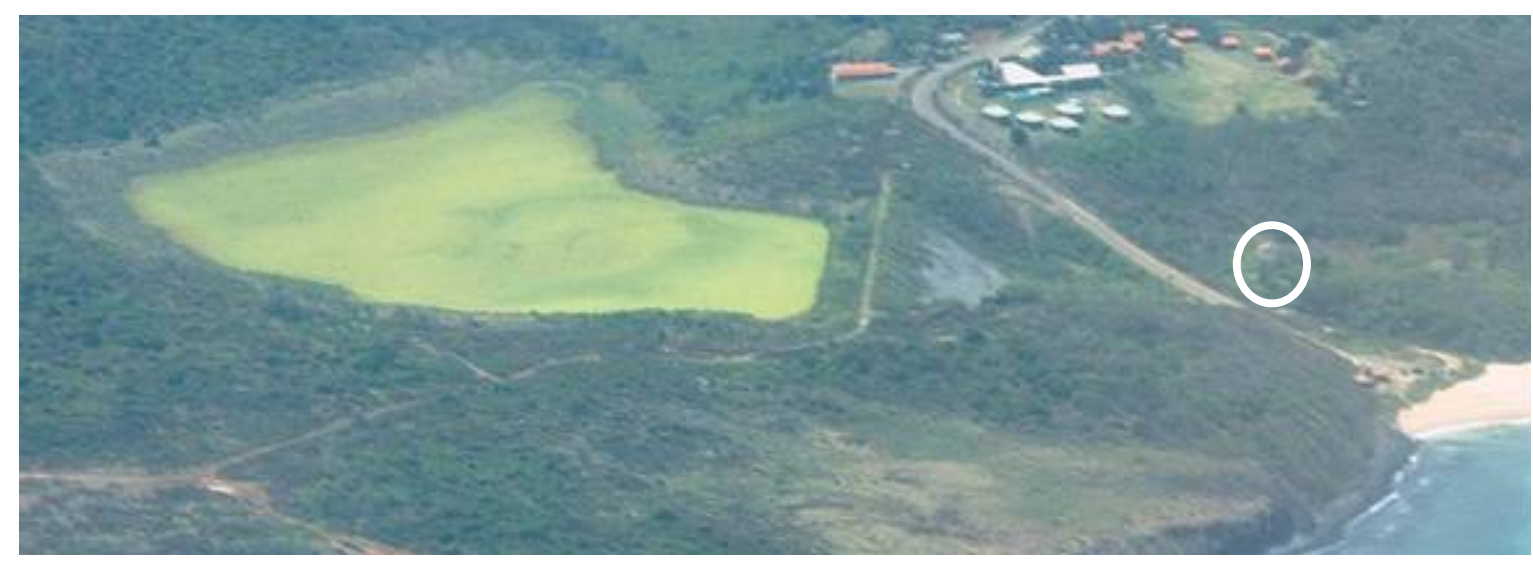

Figura 5. Vista do açude Xaréu em 22 de setembro de 2004. Detalhe para o ponto de captação de água de escoamento subterrâneo da barragem.

\section{Análises Físico-Químicas}

Pode ser observado na Figura 6a, que o teor de nitrogênio total apresentou um aumento de $43 \%$ durante o período de monitoramento, enquanto houve uma redução no teor de fósforo. Por outro lado, o teor de nitrogênio amoniacal apresentou uma ligeira queda.
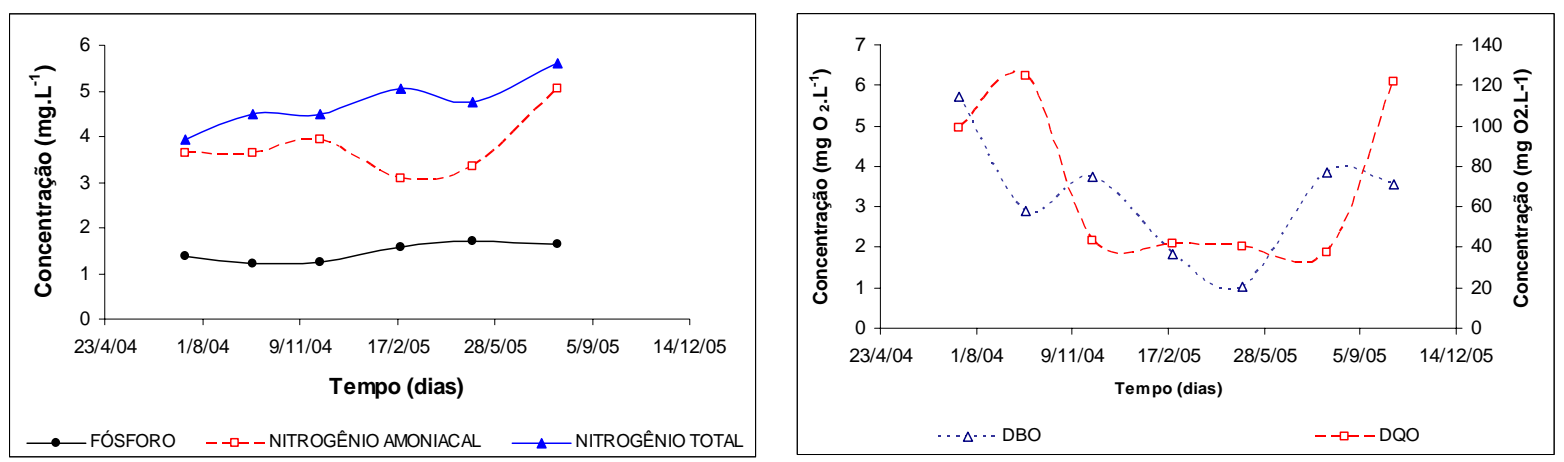

Figura 6. Variação da concentração dos nutrientes (a) e da DBO e DQO (b) da água do açude Xaréu em função do tempo.

A concentração de matéria orgânica biodegradável $\left(\mathrm{DBO}_{5}\right)$ apresentou uma redução de $82 \%$ até maio de 2005. Em seguida, após a limpeza do açude ocorreu um aumento desta. Verificou-se que a concentração de matéria orgânica (DQO) diminuiu cerca de $60 \%$ para o mesmo período, conforme pode ser visto na Figura 6 b, aumentando em outubro de 2005 . Essa redução no valor da matéria orgânica pode estar associada à diminuição no fluxo de entrada de água no reservatório, devido ao período da estiagem e à degradação realizada pelos microorganismos (bactérias) presentes no açude.

$\mathrm{O}$ aumento na concentração dos compostos nitrogenados deve ter ocorrido, provavelmente, pela redução do volume do açude. Outra possibilidade é a liberação pela decomposição das plantas, que pode ser verificada ao se comparar a evolução do nitrogênio amoniacal (Figura 6a) com a da DBO (Figura 6b). Em relação ao teor de fósforo, a sua concentração permanece estável.

O pH desse açude apresentou uma variação importante no dia 20/09/04, quando atingiu valores próximos a 3 (Figura 7a). Esse valor baixo pode ter sido um erro na análise, por problemas com o aparelho. Outra possibilidade seria o descarte de algum produto, hipótese descartada pela tipologia das propriedades localizadas próximas a esse corpo hídrico como aos seus contribuintes. A possibilidade de ter sido originado por reações biológicas 
anaeróbias também é eliminada por ter sido um valor muito baixo frente ao volume de água. Considerando-se apenas os pontos, o $\mathrm{pH}$ permaneceu em torno de 7, indicando a neutralidade da água. A condutividade elétrica apresentou valores crescentes, devido à evaporação da água e ao aumento do teor de sólidos e sais.

$\mathrm{O}$ aumento do teor de sólidos, observado pela condutividade, foi confirmado pelo aumento na concentração de sólidos totais (ST), apresentada na Figura 7b. O percentual de sólidos voláteis $(\% \mathrm{SV})$, que está associada à quantidade de matéria orgânica, apresentou inicialmente um aumento acompanhando os ST. A partir de maio de 2005, os valores voltaram a se estabilizar com valores em torno de $18 \%$.
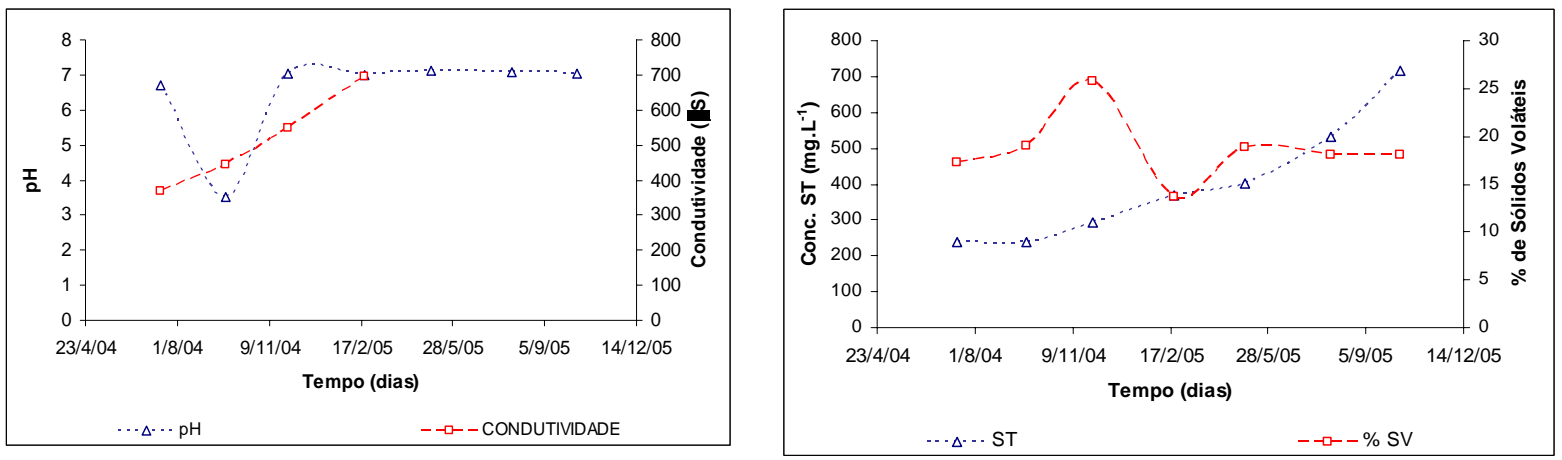

Figura 7. Variação do $\mathrm{pH}$ e da condutividade (a) e dos sólidos totais (ST) e porcentagem dos voláteis (b) em função do tempo para o açude Xaréu.

\section{Açude da Pedreira}

Esse açude funciona como sistema auxiliar para fornecimento de água para a ilha. Como pode ser observado pela Figura 8, ele se encontra com um nível muito baixo, não fornecendo mais água à ilha há vários meses. Como reservatório secundário, ele também precisa ser monitorado. No seu interior também foi constatada a presença da mesma espécie de aguapé encontrado no açude Xaréu. A limpeza do interior desse açude é necessária, possibilitando assim a remoção de vegetação, aguapés e animais mortos. Apenas em abril de 2005 foi instalada uma régua de medição do nível d'água para avaliação de sua capacidade, visando a uma melhor gestão do sistema.

Feitos esses serviços, deve-se partir para o aumento da captação de água para esse açude. A água da BR e a da pista do aeroporto pode ser enviada para este açude. Análises preliminares da qualidade dessas águas indicam a possibilidade da utilização delas para o abastecimento, após tratamento convencional.

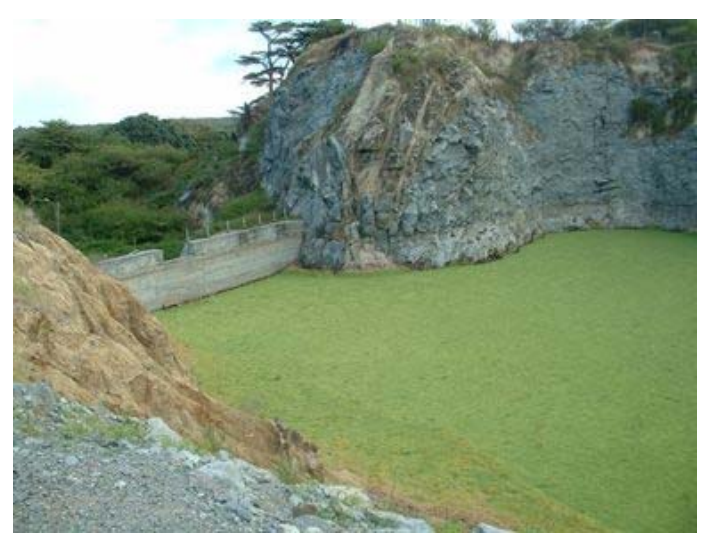

Figura 8. Vista do açude da Pedreira em Julho de 2004. 


\section{Análises Físico-Químicas}

Assim como para o açude Xaréu, foi observada também uma redução no teor de fósforo e uma ligeira queda no teor de nitrogênio amoniacal até fevereiro de 2005 e posterior aumento nos meses subseqüentes. O nitrogênio total apresentou-se relativamente estável (Figura 9a) até o mesmo mês citado e, a partir de então, começou a aumentar. As concentrações de matéria orgânica biodegradável e total apresentaram uma queda nas três primeiras análises e em seguida um aumento significativo, seguido de uma nova redução (Figura 9b).
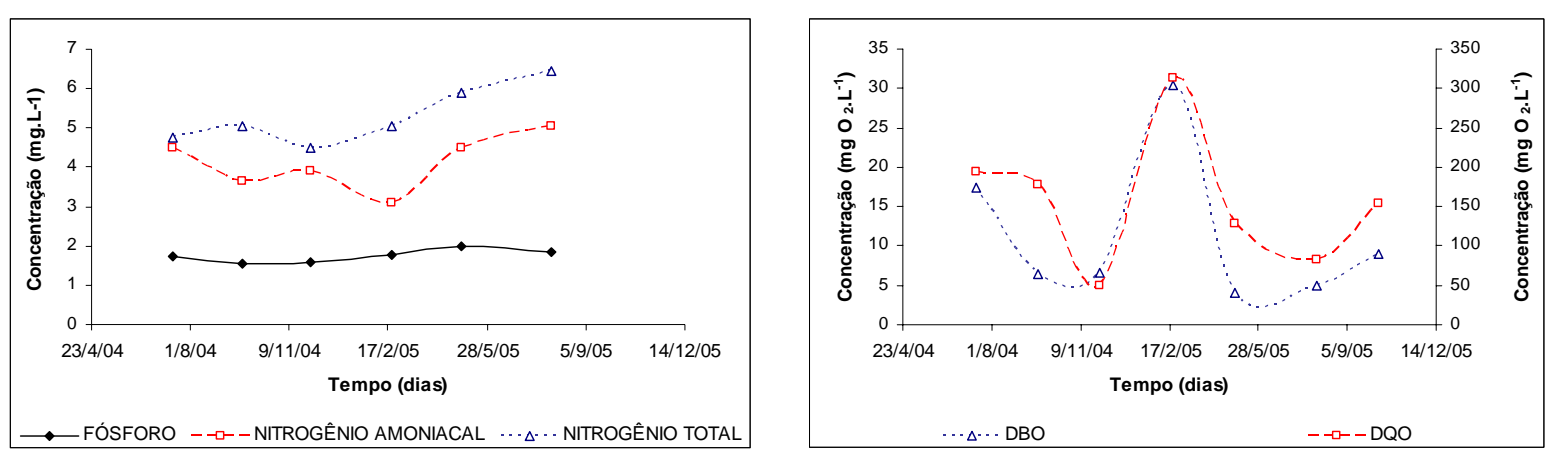

Figura 9. Variação da concentração dos nutrientes (a) e da DBO e DQO (b) da água do açude Pedreira em função do tempo.

Esse fato pode ter sido causado inicialmente pela degradação da matéria orgânica pelos microorganismos presentes no açude e, em seguida, devido à diminuição ainda maior do nível, vários aguapés morreram aumentando a matéria orgânica (Figura 9b); com a retirada dos aguapés os valores tornaram a decrescer.

A explicação da variação do teor dos compostos nitrogenados e de fósforo para esse reservatório, segue a mesma do açude Xaréu, cujo comportamento e valores se apresentam próximos ao do açude da Pedreira.

$\mathrm{O}$ pH manteve-se estável ao longo do período analisado e a condutividade elétrica cresceu devido ao aumento de sais (Figura 10a). Devido a problemas com o equipamento não se pode mais continuar o monitoramento da condutividade.

O elevado valor para a concentração de sólidos totais (ST) na primeira análise foi devido à dificuldade de coleta, provocando o arraste de lama e aumentando assim esse teor. Pode-se observar que a partir do $2^{\circ}$ ponto tem-se um aumento da concentração de ST, que está de acordo como os dados da condutividade (Figura 10b).
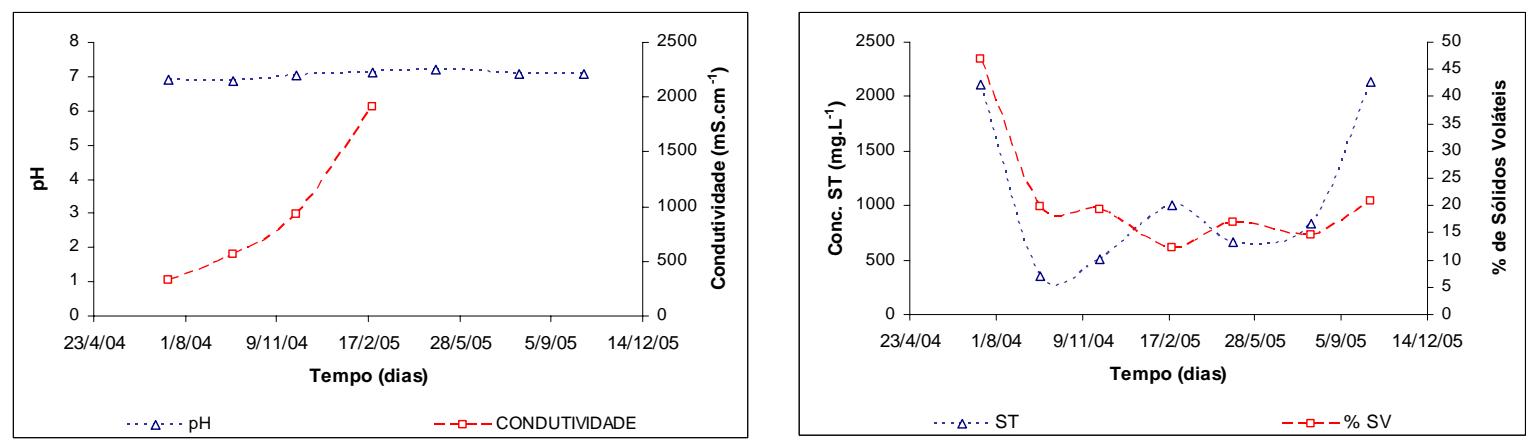

Figura 10. Variação do $\mathrm{pH}$ e da condutividade (a) e dos sólidos totais (ST) e porcentagem dos voláteis (b) em função do tempo para o açude Pedreira. 
O percentual de sólidos voláteis apresentou uma redução, indicando a degradação da matéria orgânica particulada. No primeiro ponto, quando foi arrastado um pouco de lama, pode-se verificar (Figura 10b) o elevado teor de matéria orgânica (aproximadamente 50\%).

\section{Açude Emas}

A principal utilização desse açude, Figura 11, é para a irrigação do projeto "Noronha Terra". Nesse projeto são cultivadas hortaliças para o consumo dos habitantes da ilha. No entorno desse açude, foi verificada também a criação de animais, principalmente bois e cavalos. Os excrementos desses animais podem infectar a água, reduzindo a sua qualidade. Por essa razão é importante que se faça uma cerca em torno do açude e que se coloque um sistema de drenagem para evitar não só a entrada de resíduos desses animais como também de fertilizantes, provenientes da irrigação. Essa água está com resíduos de fertilizantes que aumentam o teor de compostos nitrogenados e fosfatados na água. Foi também observada a existência de tubulações de irrigação quebradas e uma grande quantidade de girinos.

Esse açude verte para o açude do Boldró, após atravessar a BR, próximo à entrada para o forte do Boldró. Foi constatado que mesmo com o baixo nível, há uma saída de água. Essa saída é uma perda que ocorre pelo paredão ao lado da BR.

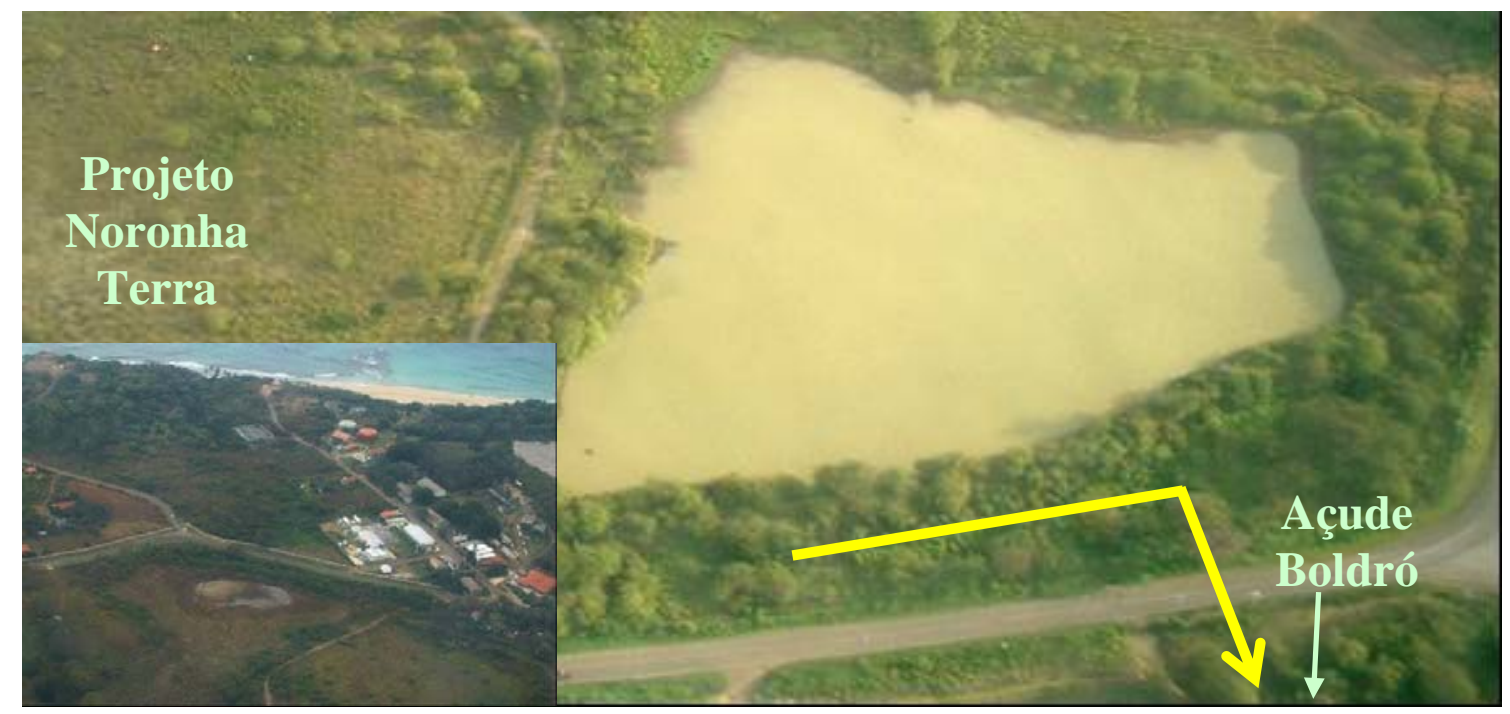

Figura 11. Vista aérea do açude Emas e a situação dele em agosto de 2005 no detalhe.

Essa água que percola a barreira da barragem (linha amarela da Figura 11), passa por baixo da BR e segue para o açude Boldró, o qual está assoreado e recebe a saída da lagoa de tratamento de efluente, cuja eficiência é muito baixa.

Uma opção bastante viável é a colocação de um dreno com um cacimbão para a coleta dessa água, a qual pode ser bombeada para estação de tratamento de água da COMPESA. Outra opção é a remoção da areia que assoreia o açude Boldró (que pode ser utilizada na construção pela administração da ilha) e o desvio da saída da lagoa de tratamento da COMPESA para jusante desse açude. Assim a água acumulada no Boldró pode ser bombeada para a estação da COMPESA.

O período da estiagem também afetou muito esse manancial, deixando-o completamente seco em agosto de 2005. Desta forma foram realizadas análises nesse corpo hídrico até o mês de maio de 2005. Vale ressaltar que no mês de maio não foi mais observada a perda de água pelo paredão, uma vez que o nível não mais o atingia. 


\section{Análises Físico-Químicas}

Foi verificado durante o período observado que os teores de nitrogênio total e de nitrogênio amoniacal mantiveram-se estáveis e redução de concentração de fósforo (Figura 12a).
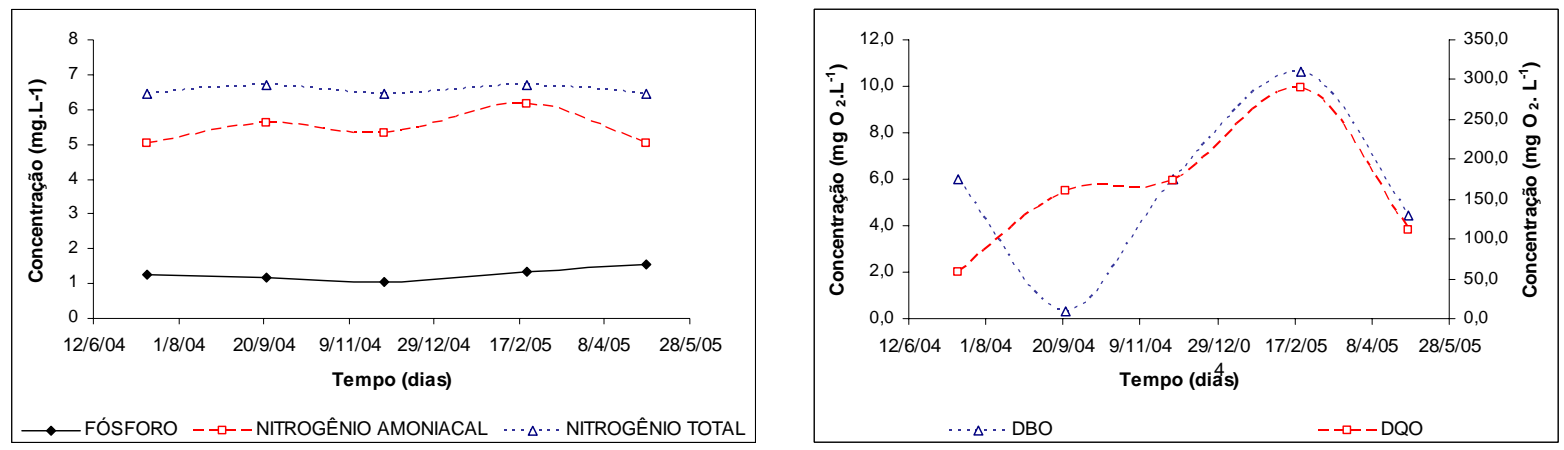

Figura 12. Variação da concentração dos nutrientes (a) e da DBO e DQO (b) da água do açude Emas em função do tempo.

Houve, contudo, um aumento substancial na matéria orgânica desse corpo d'água tanto em termos de $\mathrm{DBO}_{5}$ quanto de DQO (Figura 12b) até o mês de fevereiro de 2005. Esse aumento pode estar relacionado aos excrementos de animais e aos resíduos agrícolas e de fertilizantes. Em seguida, com a redução substancial do seu volume e não havendo mais entrada de água do retorno da irrigação nem da pecuária, esses valores foram reduzidos substancialmente.

Ao contrário dos outros açudes, as concentrações de nitrogênio amoniacal e total não apresentaram um incremento com o tempo, estando estáveis durante todo o período de monitoramento.. Esse fato vem corroborar com a justificativa para o aumento da concentração nos outros açudes, ocasionada pela degradação dos aguapés, que não estão presentes nesse reservatório. Todavia, a concentração de fósforo permaneceu estável para os outros corpos d'água.

Foram observados elevados valores do $\mathrm{pH}$ nesse açude em relação aos outros estudados (Figura 13a). Como fora citado anteriormente, esse elevado valor pode estar associado ao aporte de resíduos de fertilizantes (utilização de nitrogênio na forma amoniacal). Essa hipótese é reforçada pelos teores mais elevados de nitrogênio total e amoniacal encontrados nesse açude.
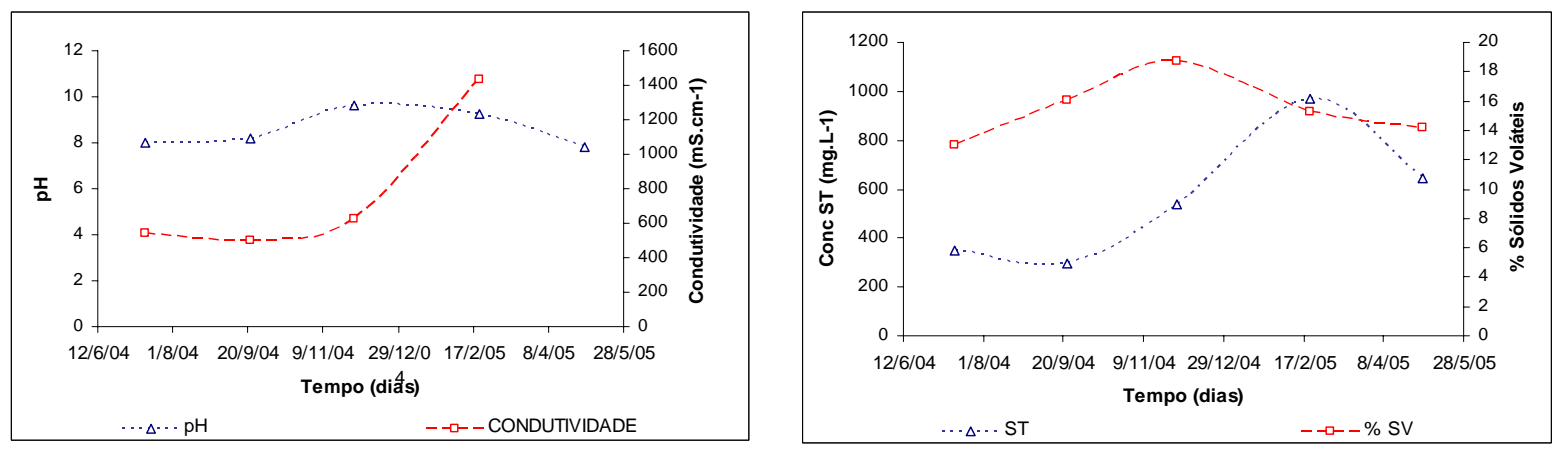

Figura 13. Variação do $\mathrm{pH}$ e da condutividade (a) e dos sólidos totais (ST) e porcentagem dos voláteis (b) em função do tempo para o açude Emas. 
Assim como para os outros dois açudes citados, foi também constatado um aumento da condutividade, sobretudo nas duas últimas análises (Figura 13a).

Além da condutividade, o teor de sólidos totais também apresentou um aumento considerável (Figura 13b). Esses fatos são devido à redução de nível do açude pela evaporação e consumo e por não haver aporte de água (proveniente da chuva). $\mathrm{O}$ valor mais elevado no mês de fevereiro pode ter sido pela presença de girinos, tendo sido necessário removê-los para que a coleta fosse realizada.

$\mathrm{O}$ açude Emas apresentou elevados valores para a turbidez. Vale então lembrar que esse é um dos dois açudes que não tem presença de aguapés. Uma hipótese para a não proliferação desse aguapé pode ser essa elevada turbidez que impede a penetração dos raios solares necessários para o metabolismo vegetal.

\section{CONCLUSÕES}

De uma forma geral, a qualidade da água dos reservatórios foi se deteriorando, devido principalmente à morte dos aguapés e á falta de chuva, com aporte de água. Todavia, a água pode ser utilizada para abastecimento após um tratamento, que com o aumento de impurezas, torna-se cada vez mais oneroso.

Pode-se constatar um aumento da concentração da DBO, DQO, sólidos e, sobretudo, da condutividade, devido à redução do volume de água e à degradação das plantas. A salinização do açude e a quantidade de matéria orgânica, podem comprometer a qualidade da água quando do novo aporte de água. Novos estudos serão realizados no sentido de se avaliar essa influência.

Foi constatado o aumento da concentração do nitrogênio amoniacal e total, devido à degradação da vegetação presente nos açudes e uma estabilidade nos valores das concentrações de fósforo.

Durante o período de monitoramento, foram feitas sucessivas campanhas para retirada dos aguapés, que tornavam a aparecer em pouco tempo. Constatou-se que no açude Emas, que apresenta elevada turbidez da água não há infestação destes, logo a transparência da água é fundamental para a reprodução das sementes dos aguapés que devem estar no interior dos açudes. Para uma remoção total dessas plantas faz-se necessário, além da remoção um tratamento com algicida que não comprometa a qualidade da água para abastecimento humano.

Uma re-estruturação do sistema de abastecimento da ilha é urgente para evitar novos problemas de racionamento e risco de colapso. A limpeza dos açudes Xaréu e Pedreira com a remoção dos aguapés, vegetação e animais mortos é necessária e atualmente está sendo realizada. Faz-se necessária também a limpeza do açude Mulungu antes que as chuvas comecem a enchê-lo, assim como a manutenção desses corpos hídricos.

É necessária uma avaliação do sistema de irrigação do projeto "Noronha Terra", para avaliar a entrada de poluentes e restos de fertilizantes e resíduos de animais no açude Emas.

Vale frisar que o abastecimento de água é fundamental para o desenvolvimento da ilha, cuja indústria principal é o turismo. Monteiro Filho e Borges (2003) citam que em 2002 a entrada de turistas na ilha ficou limitada a 180 pessoas por dia, o que representou uma redução de $20 \%$ em relação ao número de visitantes anteriores, devido à falta d'água. 


\section{AGRADECIMENTOS}

Os autores agradecem à Administração da Ilha de Fernando de Noronha, a TRIP Linhas Aéreas pelo transporte das amostras da ilha até Recife, ao CNPq pelo financiamento do projeto e aos pesquisadores que colaboram com este projeto na pessoa dos pesquisadores Ernesto Batista da Silva Filho e Noélia Mirna Martins Pereira.

\section{REFERÊNCIAS}

AMERICAN PUBLIC HEALTH ASSOCIATION (APHA). Standard methods for the examination of water and wastewater. 19. ed. Washington: APHA. AWWA. WEF, 1995.

BARROS, J. A. L. Relatório prévio sobre a expedição João Alberto à ilha da Trindade. Rio de Janeiro: [S.n.], 1959. 75 p.

CARVAlHO, F. T.; VELINI, E. D.; NEGRISOLI, E.; ROSSI, C. V. S. Eficácia do carfentrazone-ethyl no controle de plantas aquáticas latifoliadas em caixas-d'água. Planta Daninha, v. 23, n. 2, p. 305-310, 2005.

CARVALHO, L. F. A. Impactos do turismo no arquipélago de Fernando de Noronha: um estudo no caminho do desenvolvimento sustentável. 1999. 126f. Trabalho de Conclusão de Curso (Curso de Turismo) - Departamento de Relações Públicas, Propaganda e Turismo, Universidade de São Paulo, São Paulo, 1999.

COMPANHIA PERNAMBUCANA DE ÁGUA E ESGOTO - COMPESA. Elo Fernando de Noronha: um pouco que foi feito. Disponível em: <www.compesa.com.br $>$. Acesso em: 5 jun. 2007.

DA MOTTA, M. Relatório técnico de visita realizada no período de 09 a 11 de Outubro de 2005, no projeto "Disponibilidade de Recursos Hídricos Superficiais em Fernando de Noronha". Recife: Departamento de Engenharia Química, UFPE, 2005.

DA MOTTA, M., PEREIRA, N. M. M. Relatório técnico de visita realizada no período de 25 a 27 de Julho de 2006, no projeto "Disponibilidade de Recursos Hídricos Superficiais em Fernando de Noronha”. Recife: Departamento de Engenharia Química, UFPE, 2006.

KIRCHMANN, H. Animal and municipal organic wates and water quality. In: LAL, R.; STEWART, B. A. (Ed.). Soil processes and water quality: advances in soil science. Boca Raton: Lewis Publishers, 1994. p. 163-232.

KOSKI-VAHALA, J.; HARTIKAINEN, H. Assessment of the risk of phosphorus loadin due to resuspended sediment. Journal of Environmental Quality, v. 30, p. 960-966, 2001.

MONTEIRO FILHO, M., BORGES, J. Sombras no paraíso: pousadas domiciliares de Fernando de Noronha lutam para manter espaço. Problemas Brasileiros, mai.jun. 2003, p. 16-18.

MUCHOVEJ, R. M. C.; RECHCIGL, J. E. Impact of nitrogen fertilization of pastures and turfgrasses on Water Quality. In: LAL, R.; STEWART, B. A. Soil process and water quality: advances in soil science. Boca Raton: Lewis publishers, 1994. 398 p. 
OWENS, L. B. Impacts of soil N management on the quality of surface and subsurface water. In: LAL, R.; STEWART, B. A. (Ed.). Soil processes and water quality: advances in soil science. Boca Raton: Lewis Publishers, 1994. p. 137-162.

PLANTAMED. Disponível em: <http://www.plantamed.com.br/plantaservas/image/Pistiastratiotes.html>. Acesso em: 10 nov. 2005.

POTT, V. J.; POTT, A. Plantas aquáticas do Pantanal.. Corumbá: EMBRAPA/CPAP, 2000. $404 \mathrm{p}$.

ROCHA, A.T.; DUDA, G. P.; NASCIMENTO, C. W. A.; RIBEIRO, M. R. Fracionamento do fósforo e avaliação de extratores do P-disponível em solos da Ilha de Fernando de Noronha. Revista Brasileira de Engenharia Agrícola e Ambiental, v. 9, n. 2, p. 178184, 2005.

SHARPLEY, A. N. The enrichment of soil phosphorus in runoff sediments. Journal of Environmental Quality, v. 9, p. 521-526, 1980.

SHARPLEY, A.; DANIEL, T.; WRIGHT, B.; KLEINMAN, P.; SOBECKI, T.; PARRY, R.; JOERN, B. National research project to identify sources of agricultural phosphorus loss. Better Crops, n. 83, p. 12-15, 1999.

SILVA JÚNIOR, J. M. Parque nacional marinho de Fernando de Noronha: uso público, importância econômica e proposta de manejo. In: SIMPÓSIO DE ÁREAS PROTEGIDAS CONSERVAÇÃO NO ÂMBITO DO CONE SUL, 2., 13 a 15 de Out. 2003, Pelotas. . Anais... Pelotas: UCPEL, 2003. 